\title{
Pensar a cidadania a partir da comunicação
}

\section{Eduardo Yuji Yamamoto}

Doutor; Universidade Estadual do Centro-Oeste, Guarapuava, PR, Brasil yujieduardo@gmail.com

\section{Resumo}

O objetivo desse texto é refletir sobre o conceito de cidadania a partir das recentes manifestações brasileiras em redes sociais digitais, notabilizadas pelo caráter privado de suas reivindicações. Essas manifestações demandam uma investigação hermenêutica sobre a prática discursiva da cidadania na contemporaneidade. $\mathrm{Na}$ densidade semântica desse conceito, busca-se evidenciar a ideia de responsabilidade tendo como delineador a dimensão vinculativa da comunicação e da comunidade enquanto lugar de procedência comum do sujeito. $O$ texto conclui com a sugestão de pensar uma cidadania comunicacional a partir da apresentação de vidas precárias sob enquadramento impessoal.

\section{Palavras-chave}

Vinculação. Redes Sociais. Sociabilidade. Genealogia. Hermenêutica.

\section{Introdução}

A questão da cidadania, a preocupação com a justiça e a participação de diferentes grupos nas benesses civilizacionais, embora nunca tenham perdido o seu vigor reflexivo, apresentam, para alguns autores, a necessidade de uma revisão histórica e conceitual. Adela Cortina, por exemplo, contribui fundamentalmente para essa retomada teórica da cidadania, ao observar, enquanto questão essencial dos últimos anos, a "[...] falta de adesão por parte dos cidadãos ao conjunto da comunidade." (CORTINA, 2005, p. 18). 
Na década de 1990, voltou a ser atual um termo tão antigo como o de 'cidadania' nessa área do saber que os anglo-saxões designam com o vocábulo Morals, e que tem por objeto refletir tanto sobre a moral como sobre o direito e a política. Multiplicam-se então as 'teorias da cidadania', e nos discursos morais, no amplo sentido mencionado, são abundantes as referências a ela: cidadania política dos membros de um Estado nacional, cidadania transnacional, no caso de comunidades supra-estatais como a União Europeia, cidadania cosmopolita, como referência necessária de uma república mundial. (CORTINA, 2005, p. 17).

Nas pesquisas de comunicação, o diagnóstico de Cortina (2005) faz-se pertinente não apenas porque o conceito evoca objetos comunicacionais como o acesso à informação, o direito de livre expressão etc., mas, principalmente, porque sugere a ausência de práticas vinculativas de cidadania (outra dimensão da comunicação), quando indica o modo desproporcional como indivíduos indispõem-se a "sacrificar-se pelo bem comum" (CORTINA, 2005, p. 18). Contudo, eles aderem, fortemente, a projetos políticos e identitários que buscam atender a seus interesses particulares (sejam eles individuais ou coletivos) 1 .

Acredita-se que hoje, no contexto das ações comunicativas, a ideia neoliberal de indivíduos juridicamente livres e conectados por dispositivos eletrônicos tem predominado como prática discursiva da cidadania, em detrimento da obrigação pelo "conjunto da comunidade" (CORTINA, 2005, p. 18). É, justamente, este o ponto que o artigo busca problematizar: o exercício contemporâneo da cidadania, sob valoração neoliberal, tem modelado a práxis política enquanto ação de caráter privado, isto é, voltada tanto à defesa da propriedade (seja ela física ou imaginária), quanto à satisfação da identidade individual em pequenos grupos.

As recentes manifestações brasileiras em redes sociais digitais, aquelas que foram intensificadas pela crise econômica global pós-2008 e que conciliam protestos de rua e o uso de dispositivos móveis de comunicação e redes sociais digitais (a exemplo do Twitter, Facebook, entre outros) são aqui exemplares. Conforme Vladimir Safatle (2016), elas constituem um ponto de partida importante para pensar a urgência de uma prática política diferente da realizada hoje (inclusive, sob a figura da cidadania), qual seja, que organiza, competitivamente, os sujeitos em torno de propriedades e que legitima a entrega do ônus da

\footnotetext{
1 Essa desproporção é verificada também por Liszt Vieira (2001) em sua revisão conceitual da cidadania, sobretudo quando ele confronta as versões liberais e comunitaristas. Embora, haja diferenças importantes entre o comunitário e o comunitarista, no que diz respeito à ideia de comum (o primeiro implicando um conjunto indeterminado de sujeitos ou corpos políticos), a oposição apresentada por Vieira (2001) é suficiente para observar a hegemonia da versão liberal da cidadania nos dias atuais, manifestada pela ênfase sobre os direitos do indivíduo (e de seus grupos), em detrimento dos deveres e responsabilidades para com o todo social.
} 
decisão sobre seus destinos às organizações políticas institucionalizadas. Essa nova prática, segundo Safatle (2016), voltar-se-ia para a busca de uma linha de fuga capaz de conectar desejos individuais (e não identidades) e despossessões (dessubjetivações, dessubstancializações), visando outras reciprocidades, outra forma de vida em comum.

Desde 2013, subimos à cena política para dizer, em larga medida: 'Eu quero o que é meu', como se o problema todo não estivesse precisamente em falar exatamente que eu também quero a minha parte [...] No fundo e mais uma vez, o que se vê são apenas indivíduos à procura da defesa de suas propriedades. Assim, ao fazer das demandas políticas demandas de autorrealização individual e coletiva (pois nesse ponto não há diferença alguma entre os dois, o coletivo é apenas um indivíduo ampliado), acabamos por fortalecer uma ordem que afirmará 'como sempre disse, só existem propriedades e possuidores'. Ao reproduzirmos nossas demandas à pressão por reparação, fortalecemos aqueles que têm a institucionalidade que pode nos amparar [...]. Essa foi a maior vitória do neoliberalismo: definir até mesmo a gramática da nossa revolta. Não é de se admirar que a imaginação política acabe por se bloquear. Melhor seria se fôssemos aqueles que não são e nunca serão proprietários, porque procuram realizar a promessa de uma apropriação que não é possessão, porque eles se orientam por um tempo no qual não iremos mais nos perguntar sobre o que é nosso. (SAFATLE, 2016, p. 20-21).

Nesse cenário em que "só existem propriedades e possuidores", o exercício generalizado da cidadania pode estar produzindo fragmentação, isolamento e violência social, contrariando as promessas redentoras da compreensão mútua trazidas pelas tecnologias da comunicação. Em nome da cidadania (de uma suposta legitimidade que tal palavra poderia conferir às ações de defesa identitária), tal exercício tem encontrado no outro, na convivência diária, o seu limite. Um exemplo extremo dessa desproporção aconteceu em 2011, quando a usuária do Twitter (@SophiaOfDreams), "usando a liberdade de expressão para se manifestar" (REDAÇÃO, 2011a), decidiu promover ofensas raciais à região nordeste do país. Outros casos semelhantes, envolvendo figuras públicas, ganharam repercussão na media jornalística brasileira no referido ano: o deputado federal Pastor Marco Feliciano (LEMOS, 2011) e o músico Ed Motta (REDAÇÃO, 2011b), respectivamente, por meio de suas contas no Twitter e no Facebook, valeram-se desse direito para inferiorizar minorias sociais. Em 2013, diante dos protestos do Movimento Passe Livre, em São Paulo, o promotor Rogério Zagallo publicou um post no qual defendia a morte dos manifestantes em "sua" região do Tribunal de Júri, observando que o processo policial seria arquivado por ele. Questionado, o promotor defendeu-se dizendo estar se manifestado “como cidadão" (BERGAMIN JÚNIOR; BUNDUKY, 2013). 
O enfoque comunicacional que se pretende dar a presente reflexão sobre a cidadania busca problematizar a ideia de cidadão enquanto indivíduo portador de direito que, a despeito de toda convivência e civilidade - princípios que, segundo Richard Sennett (1995), implicam a presença e a ação no espaço público -, busca a realização de seus anseios individuais. Para isso, é fundamental ampliar a ideia de comunicação para além do simples ato de transmissão de informação, concebendo-a também como vinculação, o fato comunicacional cuja particularidade estaria na abertura ao outro, na ação receptiva ou sensível (muito mais do que na afirmação ou na expressão) ${ }^{2}$.

O conceito é proveniente de Muniz Sodré (2002, p. 234) que a define como “[...] formas diversas de reciprocidade comunicacional (afetiva e dialógica) entre os indivíduos. As ações vinculantes que têm natureza basicamente sociável [...]". Para o autor, a comunicação vinculativa difere-se tanto da "veiculação" quanto da "relação", já que essas cumpririam apenas uma função "societal", o "[...] contato entre sujeitos sociais por meio das tecnologias de informação [...]" (SODRÉ, 2002, p. 234), ao passo que a vinculação os compreenderia em uma comunidade.

O vínculo atravessa os limites, atravessa o corpo, os sonhos, o psiquismo do sujeito. Enquanto que a relação é o vivido, mais ou menos pronto e acabado, como ele se junta juridicamente, socialmente, a partir de convenções, de regras. A mídia trabalha a relação. Enquanto que a comunicação [vinculativa] é maior que a mídia. Ela envolve a existência mesmo. 0 núcleo dela é a comunidade. (SODRÉ, 2001, doc. não paginado).

Com essa definição, não se pretende tipificar as modalidades comunicacionais presentes nas ações humanas - visto que a vinculação, muitas vezes, está entranhada na veiculação e na relação, ou seja, nos fatos sociais mediatizados ou nos breves encontros ou acessos ao outro no cotidiano -, mas destacar a exigência do vínculo para a manutenção do social. Em linhas gerais, a comunicação vinculativa diferencia-se de suas outras modalidades pela disposição do sujeito social (o cidadão) à sociabilidade, à cooperação, portanto, pela assunção da responsabilidade pelo outro (o indivíduo qualquer que se difere dele inteiramente).

Pelo fato dessa disposição comunicacional reavivar um importante aspecto da cidadania (a responsabilidade) é que se pretende, por um lado, elucidar a sua importância

\footnotetext{
2 Autores como Ciro Marcondes Filho (2015, p. 02) têm se dedicado a esse viés sensível da comunicação (Nova Teoria da Comunicação), observando a necessidade de um "espírito aberto" ao estudo stricto da comunicação.
} 
para os tempos atuais, e, por outro lado, evidenciar a cidadania desde o referido aspecto, a partir de uma hermenêutica (ou genealogia) do conceito.

\section{Percurso metodológico}

Aplica-se aqui um procedimento hermenêutico ao conceito de cidadania. Por hermenêutica, entende-se não o esforço orientado à busca de um significado derradeiro, mas dos modos contextuais e particulares de apresentação dos objetos (sentido, significado, problemas etc.). Como assegura Sodré (1996), a hermenêutica pode convir aos estudos da comunicação, ora como crítica à univocidade intelectiva sobre os fenômenos comunicacionais, ora como modo de redefinição das práticas sociais hoje assentadas na segurança subjetiva e no suposto acabamento da técnica.

À parte dos aspectos técnicos ou culturalmente integrados, o conceito de uma 'comunicação social' também permanece como possibilidade hermenêutica (entendida tanto como teoria da interpretação quanto como prática de reconstrução do sentido histórico-cultural) de se desenvolver a reflexão sobre a diferença ontológica (heideggeriana), isto é, a diferença entre ser (o modo de aparecimento original do que existe) e ente (o existente). (SODRÉ, 1996, p. 37).

Tal hermenêutica, que se distingue da simples historicização, dada a natureza discursiva do referido conceito, rememoraria seus “[...] aspectos não historicamente explicitados [...]", encetando “[...] diálogos com a sua proveniência, com o passado, tentando apontar linhas de fuga para o pensamento metafísico." (SODRÉ, 1996, p. 38). Indicaria, nesse caso, a coexistência de práticas discursivas da cidadania na atualidade, a revelia daquelas que se impõem hegemonicamente. Uma delas é a responsabilidade, prática implicada no processo da vinculação. Daí, interessa-nos destacá-la e, posteriormente, integrá-la aos sistemas de inteligibilidade comunicacional, sobretudo pela capacidade reconstrutiva da comunicação e da cidadania.

É importante insistir nesse aspecto metodológico: a reconstrução. Tal hermenêutica, como procedimento de base, exige um trabalho complementar capaz de cessar a deriva inerente à escavação semântica, visto que da multiplicidade de práticas correlacionadas às ideias de cidadania impõe-se a determinação pragmática de contextualizá-la aos desafios e problemas do presente (no caso acima mencionado, a dificuldade de se aceitar as diferenças). Esse trabalho complementar é a redescrição. 
Reconhecidamente associada à figura de Richard Rorty (1997, p. 3), cuja percepção entendera que "[...] os problemas filosóficos poderiam ser resolvidos (ou dissolvidos) reformando a linguagem ou compreendendo melhor a que usamos no presente [...]", a redescrição é velha conhecida de pensadores da comunicação que, a propósito do estudo dos conceitos, preferem a práxis de uma dimensão semântica ao mergulho em suas profundidades metafísicas. Um exemplo é a "reforma linguística", promovida por Raquel Paiva à expressão "comunicação comunitária", dissolvendo a fronteira original da "comunidade" (definida pela sociologia do século XIX) para nela incluir (reescrever) a semântica e a prática contra-hegemônica (PAIVA, 2007, p. 137).

Por fim, aos adeptos da redescrição, cabe salientar a constante autocrítica de suas atividades, a fim de não dirimir, utilitariamente, os conceitos ou universalizar questões particulares. Ambos os gestos simplificam e reduzem o pensamento, atitude, muitas vezes, desejável do ponto de vista acadêmico-produtivo, porém temerária sob a ótica política, pois obstrui o acesso à sua potência originária e transformadora.

\section{Conceitos de cidadania}

Boa parte dos estudos sobre o conceito de cidadania tem-se definido por alguns aspectos. Um deles é a correlação com a ideia de direito. Possivelmente, incentivado pela obra Cidadania, classe social e status, de T. A. Marshall (1967), tal aspecto tem norteado pesquisas teóricas e empíricas que, em geral, adotam a trajetória histórico-cultural inglesa (a conquista sequencial do direito civil, político e social) como premissa reflexiva, não obstante, reivindicatória 3 . Outro aspecto é a sua unanimidade histórica, a ideia de que tal conceito varia no tempo e no espaço, abrindo precedentes para as diversas histórias e geografias da cidadania (PINSKY; PINSKY, 2003). Por fim, a sua forma-burguesa, ou seja, a indistinção do conceito aos valores consolidados pelas revoluções burguesas, a partir dos quais a existência do Estado, da nação e da liberdade do sujeito (individual ou coletivo) torna-se fundamental à sua manifestação.

Esses aspectos - que, de modo algum, pretendem exaurir a complexidade e as diversas faces do conceito - são importantes, na medida em que definem, como ponto de partida da investigação, a ação legitimada do sujeito em uma dada ordem social. Desse

\footnotetext{
30 trabalho de José Murilo de Carvalho (2004) indica uma quebra dessa medida pelo contexto brasileiro, pois, segundo ele, adquiriu-se o direito social antes do político e do civil.
} 
modo, sua prática, situada historicamente, amplia o escopo semântico da cidadania povoando territórios conceituais já pavimentados ou desvelando novos significados.

Nessa direção, destaca-se o trabalho genealógico empreendido por Carlos Cullen (2007). 0 pressuposto de sua investigação é semelhante àqueles que investem no tema pela via conceitual: o desequilíbrio entre a densidade histórica da palavra e seu esvaziamento retórico atual. No entanto, o que diferencia seu trabalho de outros é o que ele busca nessa investigação, ou seja, as "memórias históricas" da cidadania, a organização do conjunto de práticas cidadãs institucionalizadas e legitimadas no ocidente, mediante a qual se compreenderia as fontes do mal-estar contemporâneo - identificadas, segundo ele, como dificuldade da convivência humana -, bem como os limites e as possibilidades críticas, libertárias e sociabilizantes desse conceito.

De modo breve, descrevemos abaixo os quatro conjuntos de memórias históricas da cidadania, conforme Cullen (2007): o pertencimento, a autonomia, a resistência e a responsabilidade.

0 primeiro conjunto refere-se à circunscrição da atividade humana a uma unidade cultural de autorização, a cidade. A ideia de pertencimento é a chave para a compreensão desse conjunto, pois define o vivente que pode participar da vida social. Ele estrutura-se semelhantemente a polis grega, cujas práticas estavam todas codificadas pela bios poltikos (ou vida ativa), dela hierarquizando (e até mesmo excluindo) os viventes em um processo de degradação (de uma situação ideal à suas aparições empíricas). É a mesma racionalidade presente nas formas sociais simples da Grécia antiga (círculo de amigos) e, também, no cristianismo.

O segundo conjunto não condiciona a atividade humana e social ao pertencimento a uma "cidade", mas a outro traço universalizável, o jusnaturalismo.

A partir do mundo moderno, a cidadania não será vista como uma marca de pertencimento a uma polis, a um círculo de amigos, à natureza, a uma comunidade de fé. Começará a relacionar-se de forma clara com um modo de atuar, a de um sujeito livre. Livre, justamente, de toda dependência com relação a uma polis, um círculo, uma natureza, uma fé. É o resultado de um exercício do poder ou do direito soberano que define a natureza humana como cogito que atua e se vincula com outros cogitos. É a autonomia de um direito pré-social (direito natural), a que define uma individualidade livre e igual, que legitima, pelo pacto social, cedendo soberania a um Estadonação, também com fronteiras que definem o não-cidadão como estrangeiro, mas que o reconhecem livre ou igual, com possibilidade de aceitar o pacto constitutivo. (CULLEN, 2007, p. 26, tradução nossa). 
Um ordenamento fundado por indivíduos livres é a base dos contratualismos sociais, dos instrumentos racionais de normatização e participação na sociedade, além de ajustes eventuais no caso de uma integração problemática na comunidade. Segundo Cullen (2007), arrolam-se aqui dois grupos de pensadores: os que entendem o pacto social como exercício positivo da autonomia individual (Hobbes, Locke, Rousseau, Rawls, Taylor e Habermas), ou como dado negativo, a partir do qual o sujeito busca sua afirmação ou autenticidade (Hegel).

Neste conjunto de memória histórica, percebe-se a configuração da semântica moderna da cidadania que compõe parte das ações sociais legitimadas. Tal semântica pode ser verificada nos casos descritos no começo desse texto, na medida em que reiteram a posição absoluta e inflexível do sujeito (cogito), ou mesmo quando sugerem, conforme a lógica atomística que preside a ontologia vigente, a possibilidade de ajuntamentos sociais dominantes, a partir de uma intersubjetividade produzida por supostas substâncias comuns (classe, etnia, religião, ideologia etc.).

No entanto, e apesar dos resultados totalitários característicos desses dois conjuntos - a subsunção da vida (zoe) à política (bios), no primeiro; o apagamento das diferenças e a "ficção" da invulnerabilidade do sujeito, no segundo4 -, é possível reativar a convivência humana, a partir de outras memórias históricas, quais sejam: a resistência e a responsabilidade.

Trazida ao século XX pelos chamados filósofos da diferença - especialmente Foucault, que resgata o conceito de epiméleia heautoû dos antigos gregos -, a resistência, enquanto conjunto de práticas cidadãs, impõe a singularidade como medida universalizante da vida social e da dignidade humana. Depreende-se daí a noção de cuidado de si, estética da existência, contra os investimentos totalizadores da bios.

Isso implica que todos somos cidadãos pelo fato mesmo de viver e que a defesa da vida de todos e cada um é cidadania. Há que se trabalhar no cuidado de si e então dotar de criatividade a cidadania. 0 cuidado de si é a resistência ao disciplinamento da singularidade que se configura, sobretudo, na relação do saber com o poder. (CULLEN, 2007, p. 35, tradução nossa).

A apresentação do quarto conjunto, a responsabilidade, completa a escavação discursiva de Cullen (2007) para o conceito de cidadania no ocidente. Se os três conjuntos

\footnotetext{
4 As críticas de Cullen (2007) são pontuais às concepções cidadãs extraídas de cada pensador. Portanto, devem ser avaliadas no contexto em que o autor as coloca. Não recuperaremos este contexto que, embora importante, foge do objetivo deste texto.
} 
anteriores atingem os limites da razão pura, dos juízos assim deliberados sobre a justiça e a ação social, logo, o cogito como trincheira última do processo depurativo, na responsabilidade, o autor alarga o horizonte social, político e estético ao incluir o fora, a exterioridade absoluta que abarca as formas totalitárias, tais como aquelas decorrentes da "politização da vida" 5 , da subjetivação dialética, ou mesmo da simples alteridade eu-tu.

0 desafio consiste em entender que é a vulnerabilidade constitutiva de sabermos responsáveis, ou seja, interpelados pelo outro exterior a nossa totalidade, o único que transforma a violência em justiça. Porque por trás de toda violência está o crer-se invulnerável. É a responsabilidade, assim entendida, que faz a cidadania justa. Ser cidadão é ser responsável pelos outros, antes de todo pertencimento, toda autonomia, todo cuidado de si mesmo, como o único que justifica - torna justa - o pertencimento, a autonomia e o cuidado de si mesmo, que constituem o caráter democrático da cidadania. (CULLEN, 2007, p. 38-39, tradução nossa).

A vulnerabilidade que nos torna responsáveis prioriza o outro (e não a nós mesmos) no processo perceptivo. Nesse sentido, põe em questão tanto a cidadania enquanto ação autocêntrica do sujeito (individual ou coletivo), como a prática expressiva e afirmativa da comunicação. Tal perspectiva ético-política, sugerida por Cullen (2007) enquanto práxis escolar, pode modelar a produção de conhecimentos comunicacionais voltadas à sociabilidade e cooperação, à medida que, nessa disciplina, busque-se "[...] ensinar saberes específicos que medeiem na socialização, de modo que, na interação com esses saberes os sujeitos vão-se formando como agentes morais e políticos, com boas razões e fortes argumentos." (CULLEN, 2007, p. 17, tradução nossa).

Assim como se consolidou no ocidente uma moral pública arvorada no princípio do sujeito e da razão - a exemplo dos imperativos kantianos -, é possível que outras máximas alcancem o mesmo status, por seus fortes argumentos, a partir de traços da universalidade humana. Como a prevalência do outro (ou da comunidade) na figuração ética e como a responsabilidade enquanto pressuposto que permite escolhas (inclusive autonomizar-se do todo, isolar-se como consciência autossuficiente). As manifestações que suprimem as diferenças podem constituir aqui o limiar racional para a modelagem ética de máximas comunicacionais voltadas à civilidade.

\footnotetext{
${ }^{5} 0$ conceito refere-se à leitura de Lowith por Agamben (2002, p. 126), acerca do fenômeno já descrito da subsunção da zoe à bios.
} 


\section{Redescrevendo a cidadania}

Como recuperar esse outro no horizonte da cidadania? Como tornar comum a responsabilidade e a vulnerabilidade desde a qual se possa partilhá-las e fazê-las circular?

De fato, o investimento educacional é um caminho viável ao exercício ético da cidadania, pois envolve os sujeitos, desde o início da socialização, à convivência com o outro, os diferentes sujeitos que ocupam um mesmo território. No entanto, há também o caminho pragmático sugerido pela redescrição. Sobre isso, salienta-se a dificuldade apresentada pela forma moderna da cidadania, como se viu, fundada na primazia do cogito, cuja irredutibilidade da posição de sujeito tende tanto a reduzir o outro a um alter-ego, quanto a associar a vulnerabilidade à alienação.

Para compreender o problema, e assim traçar saídas para essa dificuldade, retomase o conceito de Outrem, de Emmanuel Lèvinas:

O Outro metafísico é outro de uma alteridade que não é formal, de uma alteridade que não é um simples inverso da identidade, nem de uma alteridade feita de resistência ao Mesmo, mas de uma alteridade anterior a toda a iniciativa, a todo o imperialismo do Mesmo; outro de uma alteridade que não limita o Mesmo, porque nesse caso o Outro não seria rigorosamente Outro: pela comunidade da fronteira, seria, dentro do sistema, ainda o Mesmo. 0 absolutamente Outro é Outrem; não faz número comigo. A coletividade em que eu digo 'tu' ou 'nós' não é um plural de 'eu'. Eu, tu, não são indivíduos de um conceito comum. (LÈVINAS, 1988, p. 26).

0 julgamento negativo à vulnerabilidade, frequentemente associada à entrega irracional aos discursos e à ideologia, tem a ver com a reificação da premissa fenomenológica que afirma a consciência transcendental - o sujeito enquanto domínio privilegiado do pensamento - como originariamente unitária e irredutível (logo, invulnerável). Portanto, recuperar o Outrem no sujeito (ponto de partida da cidadania e da comunicação) significa considerar a vulnerabilidade não um problema para o sujeito (o qual esse deveria evitar em nome de sua autonomia ou autenticidade), mas a condição mesma de sua identificação.

Essa precedência de um "terceiro", que perturba a ordem estável das relações, tem sido objeto de importantes reflexões sobre as possibilidades atuais do viver junto, de uma vida coletiva em comum. Tendo como pano de fundo as catastróficas experiências políticas totalitárias e os fundamentalismos religiosos do século $\mathrm{XX}$, formas sociais gestadas no ideal comunitário, pensadores como Jean-Luc Nancy redescreveram a ideia de comunidade como 
um "terceiro" da relação, modelando o termo no mesmo plano metafísico do Outrem levinasiano, isto é, no campo da precedência ontológica ou existencial.

À luz do pensamento de Martin Heidegger, Nancy (2000) redefine a comunidade como ser-com ou estar-em-comum (Mitsein), dimensão originária do sujeito (Dasein).

A comunidade não é um predicado do ser ou da existência. Não se altera nada no conceito de existência adicionando ou extraindo o caráter de comunidade. Mas a comunidade é simplesmente a posição real da existência. (NANCY, 2000, p. 97, tradução nossa).

O conceito heideggeriano de Mitsein, diz Nancy (2000), deveria ser compreendido na própria fenomenologia de Heidegger, isto é, Mit como condição existencial do Dasein e não como algo que o complementa posteriormente. Em outras palavras, Dasein constitui-se como tal, a partir de uma mundaneidade ou comunidade (Mitdasein) nele pressuposta; somente à custa do esquecimento dessa condição mundana ou comunitária é que Dasein institui-se como sujeito soberano. A releitura da comunidade por Nancy (2000) é importante para a averiguação de hipóteses históricas sobre a consagração da ideia de cidadão enquanto indivíduo portador de direito e sujeito ativo (expressivo, afirmativo) da comunicação.

A pesquisa etimológica, realizada por Roberto Esposito, sobre o conceito de comunidade, oferece algumas pistas neste sentido. A partir de sua raiz latina (communitas = cum+munus), Esposito (2007) chega não só à condição prévia da comunidade sobre o indivíduo, isto é, a dívida (munus) para com (cum) a comunidade que os indivíduos carregam antes de se autonomizarem no cogito, mas também ao momento em que se dá tal ficção: “[...] um 'dever' une os sujeitos da comunidade - no sentido de que 'te devo algo', e não no sentido de que 'me deves algo' - que faz com que não sejam inteiramente donos de si mesmo." (ESPOSITO, 2007, p. 31, tradução nossa).

A ficção do cogito, segundo Esposito (2007), é descrito como um conjunto de determinações históricas advindas com a emergência da modernidade e das práticas discursivas que a constitui como ruptura, qual seja, a transição da com-munitas para a inmunitas e a mudança na postura do indivíduo frente ao outro, de uma dívida (munus) para com ele (uma vida sociável, afetiva, dialógica), para a neutralização dessa mesma dívida (uma vida in-munizada, apartada do todo). Daí, diz Esposito (2007, p. 40, tradução nossa), decorreu o "golpe hermenêutico" que deu ao Homem uma origem fictícia no cogito 
imunizado, a partir do que se pode inferir sua aparição na consciência transcendental da fenomenologia, no sujeito histórico da filosofia ou, no caso da comunicação, na figura do emissor.

Recuperar essa dimensão esquecida da comunidade - lembrada, entretanto, por Nancy (2000) e Esposito (2007) - ajudar-nos-ia na tarefa de reanimar a responsabilidade como prática da cidadania contemporânea. Essa tarefa, entretanto, necessita da ampliação do conceito de comunidade para além de sua afirmação substancialista, uma vez que implica no regresso ao plano metafísico, existencial, de Lèvinas e Heidegger, observando-o como lugar de procedência comum do indivíduo. Gilles Deleuze (19956 apud AGAMBEN, 2000, p. 178) chamou esse plano de "imanência absoluta", porém, curiosamente em seu último escrito, nominou-o também de "uma vida".

À procura de uma imagem de pensamento que pudesse traduzir esse plano filosófico, Deleuze (1995) oferece uma cena da obra Our mutual friend, de Charles Dickens, em que o personagem Riderhood, um sujeito ruim, desprezado por todos, está prestes a morrer e as pessoas ao redor apressam-se a salvá-lo: “[...] no coma mais profundo, o malvado sente algo terno invadindo-o. Mas à medida que ele volta à vida seus salvadores se tornam frios, e ele recupera toda sua grosseria e maldade." (DICKENS, $1989^{7}$ apud AGAMBEN, 2000, p. 179).

No limiar entre a vida e a morte, diz Deleuze (1995), uma "centelha de vida" resplandece e a vida não é mais aquela do sujeito bom ou mau. É a vida impessoal. É a humanidade, enquanto comunidade humana sem substância, que comparece aí como imanência absoluta da vida (ou do humano), fonte das individuações: Homo Tantum.

Se a prática da cidadania, enquanto responsabilidade pelo outro, é possível na comunicação, essa prática voltar-se-ia para a visibilidade pública dessa "vida impessoal", essa humanidade que nos comuniza dentre tantas diferenças, para que, nessa apresentação, mobilize-se a defesa da vida - não de uma vida em particular, de um ente querido ou de um amigo distante, mas da vida qualquer que se põe em perigo.

No referido episódio, Deleuze descreve um momento de beleza, uma "espécie de beatitude" (1995 apud AGAMBEN, 2000, p. 179), diante do sofrimento e quase morte do inimigo. Talvez, a chave para o exercício da responsabilidade cidadã esteja nesse momento

\footnotetext{
${ }^{6}$ DELEUZE, Gilles. L'immanence: une vie... Philosophie, [S.l.], n. 47, 1995, p. 3-7.

7 DICKENS, Charles. Our mutual friend, Oxford, 1989, p. 443.

8 DELEUZE, Gilles. L'immanence: une vie... Philosophie, [S.l.], n. 47, 1995, p. 3-7.
} 
de comunhão estética, que não é a satisfação pelo sofrimento ou pela morte do outro, mas, do contrário, a vulnerabilidade que o evento nos endereça, a percepção de ver o humano onde, anteriormente, havia um canalha ou, ainda, de ver "só um homem" ali onde, antes, nada existia.

\title{
5 Conclusão
}

Os meios técnicos de comunicação, as empresas que administram a distribuição, a circulação e o armazenamento de informações, além dos usuários que utilizam esses meios e serviços, estruturam as condições contemporâneas de visibilidade e representação pública dos fatos sociais.

Em seu texto Vida precária, Judith Butler (2004) problematiza os "esquemas normativos de inteligibilidade" mediática que fazem com que certas imagens de sofrimento e morte atinjam o espaço de visibilidade pública, a fim de torná-las dignas de lamentação ou, do contrário, de ódio e esquecimento.

\begin{abstract}
Esses esquemas normativos operam não apenas produzindo ideais do humano que diferenciam entre aqueles que são mais e aqueles que são menos humanos. Às vezes, eles produzem imagens do menos que humano, à guisa do humano, para mostrar como o menos humano se disfarça e ameaça enganar aqueles de nós que poderiam pensar que conseguem reconhecer outro humano ali, naquele rosto. Mas, às vezes, esses esquemas normativos funcionam, precisamente, sem fornecer nenhuma imagem, nenhum nome, nenhuma narrativa, de modo que ali nunca houve vida e, portanto, nunca houve morte. (BUTLER, 2004, p. 146, tradução nossa).
\end{abstract}

A discussão de Butler (2004), embora situada no âmbito das estratégias governamentais, auxilia-nos a repensar a prática comunicacional diária, aquela que se desenvolve ao nível dos cidadãos. Do ponto de vista da "relação" e da "veiculação" (SODRÉ, 2001; 2002), poderíamos nos interrogar sobre como esses "esquemas normativos" incidem sobre nós, individualizando-nos juridicamente; ou ainda, em que medida esses esquemas são por nós reproduzidos quando atualizamos, em tweets e posts, a estrutura nós contra eles. Um tópico sobre a analítica do poder moderno que, embora necessário, não desenvolveremos aqui, mas que elucida o trabalho mediático que se tem pela frente - um trabalho de inclusão das alteridades - neste contexto de disputa pela visibilidade pública, das construções mediáticas de inumanos (Osama Bin Laden, Saddam Hussein, Riderhood 
etc.) e de forclusões, eventos que se tornam possíveis quando a responsabilidade pelo outro retira-se do horizonte das práticas da comunicação expressiva.

Por outro lado, do ponto de vista da vinculação, poderíamos nos interrogar em que medida essas imagens de sofrimento nos atingem, ou em que medida nos sentimos mais ou menos vinculados às alteridades que têm suas vidas fragilizadas?

Quando, em 2013, alguns ativistas brasileiros iniciaram a campanha "Onde está o Amarildo?", referente ao desaparecimento de Amarildo de Souza após sua condução coercitiva pela polícia do Rio de Janeiro, e o rosto do pedreiro circulou pelas redes sociais, a invisibilidade da violência policial sobre os moradores pobres da periferia ruiu, tornando-se pauta de alguns veículos de comunicação do país. 0 rosto de Amarildo estampou camisetas e cartazes, inspirando ativistas de países como a República Dominicana que buscou a mesma visibilidade pública para seus desaparecidos: ¿Dónde está Juan Almonte?

Na trilha levinasiana, Butler (2004) observa que a vinculação a um rosto como o de Amarildo não se dá por uma simpatia a uma classe social, mas pelo humano que o precede e que nos humaniza: "Levinas deixou claro que o rosto não é exclusivamente um rosto humano e, ainda, é uma condição para a humanização." (BUTLER, 2004, p. 141, tradução nossa).

Em algumas experiências brasileiras, essa humanização tem-se mostrado em níveis e modos variados. A proposta do Movimento Passe Livre, por exemplo, atinge esse grau de humanização quando propõe uma crítica aos modelos urbanísticos que beneficiam (ou individuam a cidade para) alguns grupos, mas, sobretudo, quando estende a mobilidade ao público indeterminado, permitindo a todos uma circulação sem obstáculos e o uso heterogêneo da cidade para realização de suas potências vitais.

[...] 'Não são os centavos, são nossos direitos'. Porque, como todos os outros movimentos do mundo, ao lado de reivindicações concretas, que logo se ampliaram para educação, saúde, condições de vida, o fundamental foi - e é - a defesa da dignidade de cada um. Ou seja, o direito humano fundamental de ser respeitado como ser humano e como cidadão. (CASTELLS, 2013, p. 144).

A nosso ver, uma práxis comunicacional voltada à cidadania estaria incompleta se apenas viabilizasse o acesso ao conhecimento jurídico e ao saber técnico laboral, excluindo o homem e a cidade humana de sua ação teórica e prática. A produção e a circulação de imagens não são suficientes para perceber que nossa comunidade é mais ampla do que 
imaginamos, é que se faz preciso exercitar a vinculação, essa capacidade de reconhecer o humano onde os media não enxergam, mas que também nós mesmos, muitas vezes, recusamos.

O aprofundamento no viés ético-político da cidadania apresenta, obviamente, questões desafiadoras: quais saberes específicos (ou quais procedimentos autorreflexivos) devemos realizar para produzir uma sensibilização eficiente do outro? Quais demandas são mais urgentes, ou qual outro devemos privilegiar? Responder a todos os outros não seria uma irresponsabilidade? É possível evitar a autopreservação ainda mais quando o outro ameaça a minha vida?

A ausência de respostas decisivas para esses questionamentos de modo algum pode ser desanimadora. Do contrário, uma linha de fuga do pensamento seria desestimulante se não colocasse muitos desafios. A exigência que se põe aqui, entretanto, à ação cidadã responsável, é deslocar o humano sobre a moldura onde hoje se encontra apenas o cidadão.

\section{Agradecimentos}

0 autor agradece à Unicentro pelo apoio à pesquisa e aos pareceristas e revisores anônimos pelas críticas, correções e sugestões da versão anterior deste manuscrito.

\section{Referências}

AGAMBEN, G. Homo sacer: o poder soberano e a vida nua. Belo Horizonte: UFMG, 2002.

AGAMBEN, G. Imanência absoluta. In: ALLIEZ, E. (Org.). Gilles Deleuze: uma vida filosófica. São Paulo: Editora 34, 2000. p. 169-192.

BERGAMIN JÚNIOR, G; BUNDUKY, R. Promotor incita violência contra manifestantes e depois pede desculpas. Folha de S. Paulo, São Paulo, 10 jun. 2013. Cotidiano. Disponível em: <http://www1.folha.uol.com.br/cotidiano/2013/06/1292476-promotor-incita-violenciacontra-manifestantes-e-depois-pede-desculpas.shtml>. Acesso em: 24 abr. 2016.

BUTLER, J. Precarious life. In: BUTLER, J. Precarious life: the powers of mourning and violence. London: Verso, 2004. p. 128-151.

CARVALHO, J. M. Cidadania no Brasil: o longo caminho. Rio de Janeiro: Civilização Brasileira, 2004. 
CASTELLS, M. Redes de indignação e esperança. Rio de Janeiro: Zahar, 2013.

CORTINA, A. Cidadãos do mundo: por uma teoria da cidadania. São Paulo: Loyola, 2005.

CULLEN, C. A. Cuidadanía urbi et orbi: desventuras de um concepto histórico y desafios de um problema contemporâneo. In: CULLEN, C. A. (Org.). El malestar en la cuidadanía. Buenos Aires: La Crujía, 2007. p. 17-42.

DELEUZE, G. L'immanence: une vie... Philosophie,[S.l.], n. 47, p. 3-7, 1995.

DICKENS, C. Our mutual friend. Oxford: Oxford University Press, 1989.

ESPOSITO, R. Communitas: origen y destino de la comunidad. Trad. Carlo Rodolfo Molinari Marotto. Buenos Aires: Amorrortu, 2007.

LEMOS, I. Deputado vê 'podridão' em gays e diz que há 'maldição' sobre africanos. G1, Brasília, 31 mar. 2011. Política. Disponível em: <http://g1.globo.com/politica/noticia/2011/03/deputado-ve-podridao-em-gays-e-diz-queafricanos-sao-amaldicoados.html>. Acesso em: 24 abr. 2016.

LÈVINAS, E. Totalidade e infinito. Lisboa: Edições 70, 1988.

MARCONDES FILHO, C. De como a comunicação choca, revela, nos traz de volta ao mundo. ECompós, Brasília, v. 18, n. 1, p. 1-12, 2015.

MARSHALL, T. H. Cidadania, classe social e status. Rio de Janeiro: Zahar, 1967.

NANCY, J-L. La comunidad inoperante. Santiago de Chile: ARCIS, 2000.

PAIVA, R. Para reinterpretar a comunicação comunitária. In: PAIVA, R. (Org.). 0 retorno da comunidade. Rio de Janeiro: Mauad X, 2007. p. 133-148.

PINSKY, J.; PINSKY, C. B. (Org.). História da cidadania. São Paulo: Contexto, 2003.

REDAÇÃO. Gaúcha fala mal do Nordeste no Twitter e causa revolta; Salvador é elogiada. Correio, Salvador, 9 dez. 2011a. Brasil. Disponível em:

<http://www.correio24horas.com.br/detalhe/noticia/gaucha-fala-mal-do-nordeste-notwitter-e-causa-revolta-salvador-e-elogiada/>. Acesso em: 24 abr. 2016.

REDAÇÃO. Ed Motta causa revolta xingando mulheres e cantores da MPB no Facebook. Veja.com, 13 mai 2011b. Entretenimento. Disponível em: <http://veja.abril.com.br/noticia/entretenimento/ed-motta-causa-polemica-xingandomulheres-e-cantores-da-mpb-no-facebook>. Acesso em: 24 abr. 2016.

RORTY, R. The linguistic turn: recent essays on philosophical method. Chicago: University of Chicago Press, 1997.

SAFATLE, V. Quando as ruas queimam: manifesto pela emergência. São Paulo: n-1, 2016. 
SENNETT, R. 0 declínio do homem público: as tiranias da intimidade. São Paulo: Companhia das Letras, 1995.

SODRÉ, M. Antropológica do espelho: uma teoria da comunicação linear e em rede. Petrópolis: Vozes, 2002.

SODRÉ, M. Objeto da comunicação é a vinculação social. PCLA, São Bernardo do Campo, v. 3, n. 1,out. 2001.

SODRÉ, M. Reinventando a cultura: a comunicação e seus produtos. Petrópolis: Vozes, 1996.

VIEIRA, L. Os argonautas da cidadania: a sociedade civil na globalização. Rio de Janeiro: Record, 2001.

\title{
Thinking about citizenship from the communication perspective
}

\begin{abstract}
The aim of this paper is to think about the concept of citizenship based on the recent Brazilian manifestations in the digital social networks highlighted by the private character of their claims. These manifestations require a hermeneutics research about the discursive practice of citizenship in the contemporary time. In the semantic density of this concept, we intend to highlight the idea of responsibility by having as delineator the communication as a binding practice and the community like a place of common origin from the subject. Finally, the text suggests thinking about a communicational citizenship, that is, the presentation of precarious lives from an impersonal frameworking.
\end{abstract}

\section{Keywords}

Binding. Networks. Sociability. Genealogy. Hermeneutics.

Recebido em 27/06/2016

Aceito em 14/12/2016 